\title{
Diverticule of the Uretra on Uretral Stenosis: about A Case and Review of the Literature
}

Sabra Bezzanin*, Z. Aboulam, R. Oulahyane, M. Kissra

Department of Visceral and Urological Pediatric Surgery, Children's Hospital, Faculty of Medicine and Pharmacy of Rabat, University Mohammed V. Rabat, Morocco

DOI: $10.36347 /$ sasjs.2020.v06i06.003

| Received: 06.06.2020 | Accepted: 13.06.2020 | Published: 26.06.2020

*Corresponding author: Bezzanin Sabra

\section{Abstract}

The male urethral diverticulum is a rare clinical entity. Whether congenital or acquired, the clinical symptomatology is identical. We report the observation of a diverticulum of the urethra in a 2 year old boy treated in the pediatric surgery department - A-Children's Hospital Rabat. Treatment was based on diverticulectomy and urethroplasty. Through this observation and a review of the literature, the authors briefly describe the pathological and therapeutic aspects of the diverticulum of the urethra.

Keywords: Diverticulum, urethra, diverticulectomy, ureteroplasty, meatoplasty.

Copyright @ 2020: This is an open-access article distributed under the terms of the Creative Commons Attribution license which permits unrestricted use, distribution, and reproduction in any medium for non-commercial use (NonCommercial, or CC-BY-NC) provided the original author and source are credited.

\section{INTRODUCTION}

The diverticulum of the urethra is a rare entity in children. It produces a sub-urethral pocket or suburethral cyst, it is a cul de sac lined with mucosa without a coordinated functional muscle layer and therefore are areas of urinary stasis and infection, of origin most often acquired. The congenital form remains exceptional. Through an observation of an acquired diverticulum of the urethra after stenosis of the urethral meatus during surgery for an epispadias, the epidemiological, diagnostic and therapeutic aspects of this rare condition will be discussed.

\section{PATIENT AND OBSERVATION}

2 year old boy, operated 1 year ago for epispadias. Who presented for 2 months repetitive urinary tract infections with an episode of bladder retention. In addition, the mother reported the appearance of a fine urinary stream associated with post-voiding flow and an increase in scrotal volume intermittently. The clinical examination showed a mass of bilateral scrotal fluid consistency and a narrowed urethral meatus. The rest of the clinical examination was without particularity. A scrotal ultrasound objectified a bilateral hydrocele of great abundance, ECBU was still infected. After preoperative assessment, the child underwent resection of the urethral diverticulum (Figure $1 \&$ 2) associated with a urethroplasty (Figure-3) and a meatoplasty (Figure-4). The postoperative follow-ups were simple.

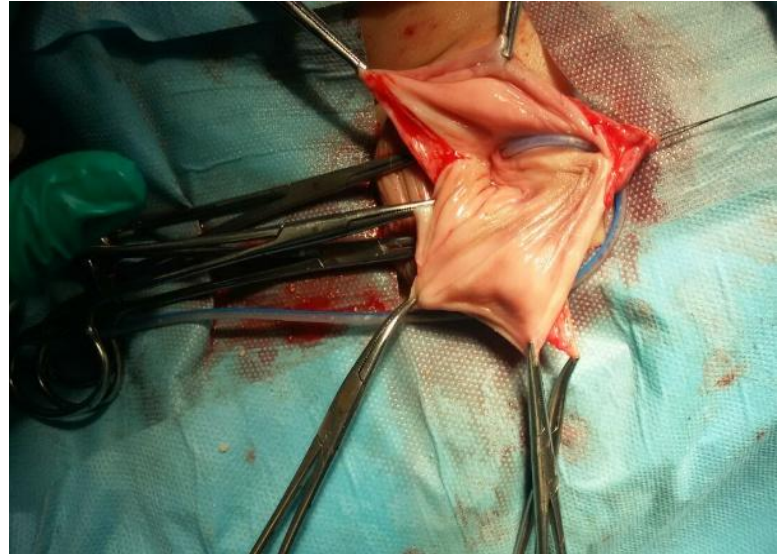

Fig-1: Diverticular discovered in perioperative

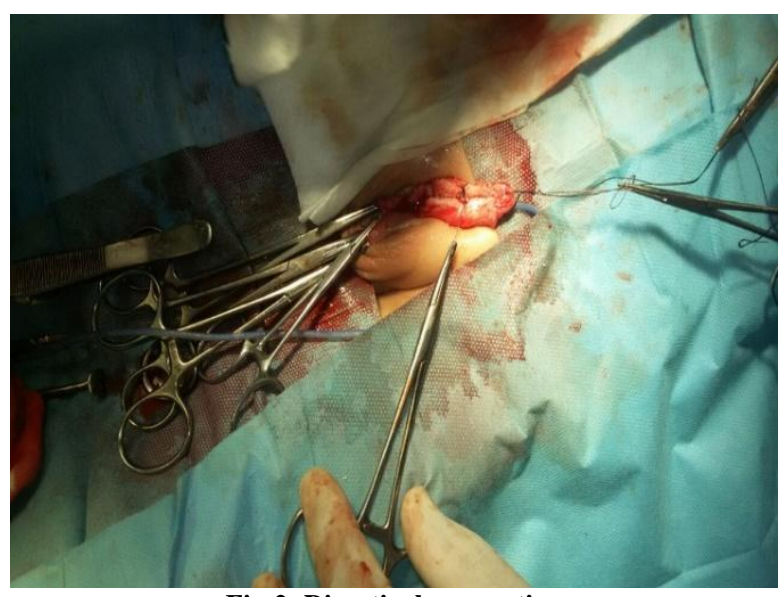

Fig-2: Diverticular resection 


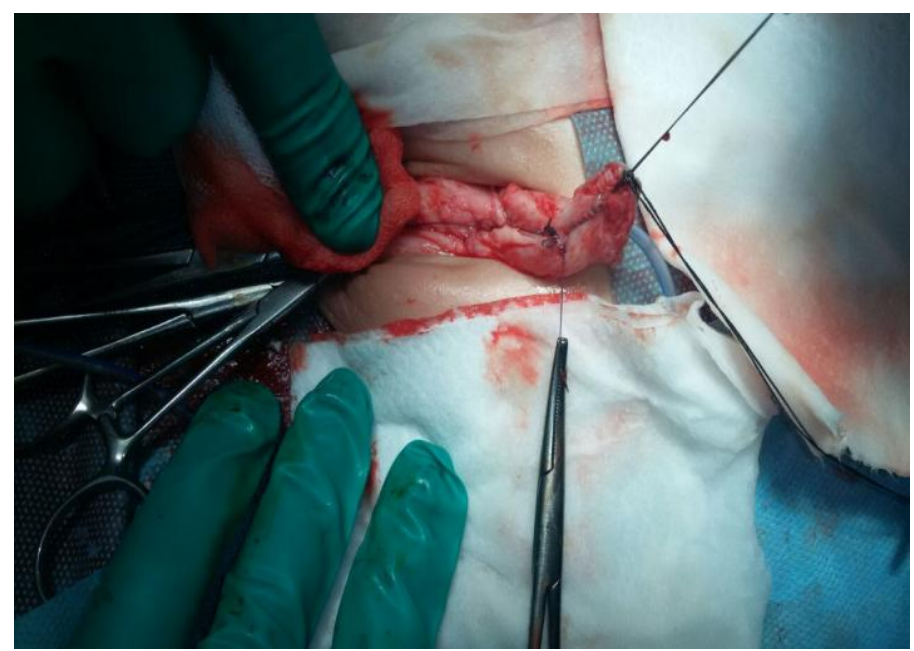

Fig-3: Urethroplasty

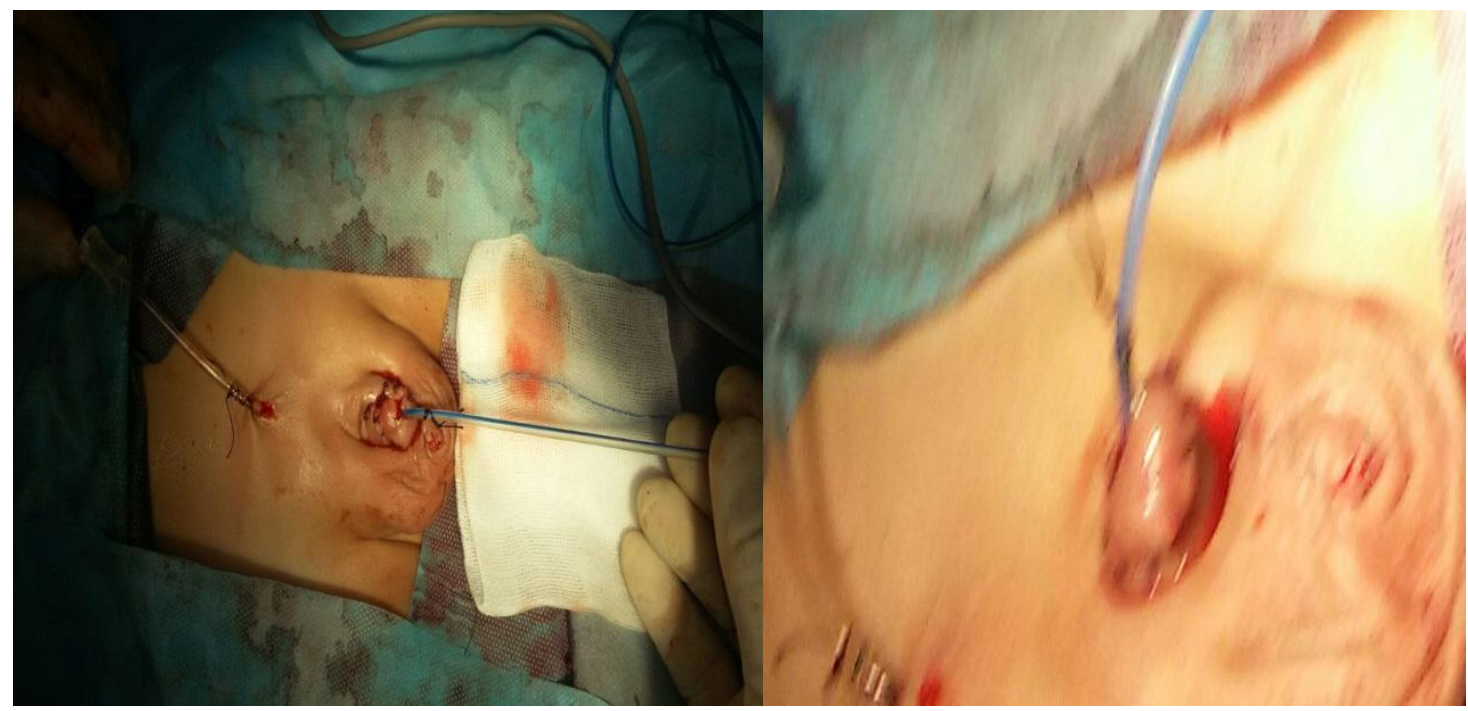

Fig-4: Meatoplasty and cystostomy

\section{DISCUSSION}

Urethral diverticulum in children is a rare condition. Its incidence varies between $0.5 \%$ and $6 \%$, with a clear predominance in girls [1-3]. The acquired form is by far the most frequent [3]. The primary congenital diverticulum is much less frequent [2]. Its etiopathogenesis is based on various theories including that of Hancen, who reports the possibility of the occurrence of the diverticulum of the urethra by cystic dilations of the canaliculi of the Cowper glands [1]. For others, the congenital diverticulum represents the expression of an embryological abnormality by an abnormality of development of the urethral plate and the fusion of the genital folds. The acquired forms are generally secondary to a break in of the urethral wall during a pelvic trauma [4]. Other etiopathogenic mechanisms can be involved, in particular, instrumental manipulations, peri-urethral suppurations, urethral lithiasis, after wearing a urinary catheter for a long time and after urethroplasty in $1.5 \%$ to $18 \%$ of cases. Their preferred location remains the penoscrotal angle $[5,6]$. Clinically, it can be revealed by repeated urinary tract infections, hematuria, post-voiding drip, dysuria, swelling of the penis. Intradiverticular stones by urinary stasis [6]. Monitoring may be recommended for the small asymptomatic diverticulum. In case of symptomatic or large diverticulum (as in our case), a gesture is necessary. Several topographies of diverticula are possible, the proximal diverticula correspond to an evagination of the ventral urethra in the cancellous body, at the penile junction scrotal. They manifest as dysuria. During voiding images, the urethra upstream of the diverticulum is distended while the downstream urethra is thin. The distal, juxta-balanic, dorsal or ventral diverticula generally have no functional repercussions [7]. The opacification of the Cowper's glands results in a diverticular image, in the bulbar portion, appended to the lower edge, in saccular form or of a pseudo ascending path parallel to the urethra [13]. The opacification of the prostatic utricle can be observed, in the form of a very fine diverticulum of a few millimeters to a centimeter in length [8] Ultrasound allows to visualize the diverticulum and also to study finely the walls of the urethra $[9,10]$. Urethroscopy also makes it possible to visualize the diverticulum [10]. Surgical repair involves completely excising the 
diverticulum, restoring the continuity of the urethra and covering it with good quality tissue to strengthen the repair and prevent the risk of fistula [11]. For our patient, diverticulectomy was associated with urethroplasty and meatoplasty. In the case of obstructive diverticulum, some authors recommend endoscopic resection of the lower lip of the diverticulum allowing the removal of obstacle; and secondarily, if necessary, diverticulectomy can be performed. In the event of an infected diverticulum, a two-step procedure can be proposed: first perineal urethrostomy then secondary treatment of the diverticulum [12] The evolution after surgery can be done towards the installation of fistulas by necrosis of the banks, suture release and by local suppuration [13]. It can also be complicated by urethral stenosis or recurrences [13].

\section{CONCLUSION}

This observation illustrates the possibility of the occurrence of a diverticulum of the urethra in the infant with meat stenosis after surgical treatment of epispadias, In this context, any usual mass of the penis after repair of epispadias must evoke the diagnosis of a diverticulum of the urethra and perform urinary urethrography. In case of symptomatic or large diverticulum, the surgical procedure is essential. For asymptomatic forms, treatment remains solely on the achievement of manual pressure of the urethra at the level of the diverticulum at the end of urination and the use of periodic antibiotic prophylaxis to prevent infections.

\section{REFERENCE}

1. Older RA, Hertz M. Cystourethrography in Pollack HM, McCleenan BL. Clinical Urography, WB Saunders Company, Philadelphia, 2000, 303355.

2. Stephens FD. The male urethra. In Congenital malformations of the urinary tract. Praeger, New York, 1983.

3. Mohan V, Gupta SK, Cherian J, Tripathi VN, Sharma BB. Urethral diverticulum in male subjects: report of 5 cases. The Journal of urology. 1980 Apr;123(4):592-4.

4. Auvigne. Ablation des diverticules. Encycl Med Chi, 1981; 41330.

5. Bryden AG, Gough DS. Traumatic urethral diverticula. BJU international (Papier). 1999;84(7):885-6.

6. Dmochowski R. Urethral diverticula: evolving diagnostics and improved surgical management. Current urology reports. 2001 Sep 1;2(5):373-8.

7. Elbakry A. Complications of the preputial island flap-tube urethroplasty. BJU international. 1999 Jul;84(1):89-94.

8. El Mrini M, Bennani S, Aboutaieb R, Joual A, Benjelloun S. L'uréthrocèle chez l'homme. Journal de chirurgie (Paris. 1908). 1993;130(8-9):371-3.

9. Mohan V, Gupta SK, Cherian J. Urethral diverticulum in male subjects. Report of 5 cases. Journal of urology, 1980; 124: 350.

10. Monish A, Rajeev TP, Dorairajan LN, Gupta NP. Infected congenital urethral diverticulum in an adult male. Urologia internationalis. 1999;62(3):177-9.

11. Ortlip SA, Gonzalez R, Williams RD. Diverticula of the male urethra. The Journal of urology. 1980 Sep;124(3):350-5.

12. Özgo Y, Seckin B, Demirci S, Harmankaya C, Erduran D, Sinav A. Surgical treatment of urethral diverticula in men. Scandinavian journal of urology and nephrology. 1994 Jun 1;28(2):20710.

13. Ryu JA, Kim B. MR imaging of the male and female urethra. Radiographics. 2001 Sep;21(5):1169-85. 